\title{
Attitudes towards Life and Death in Europe: A Comparative Analysis*
}

\author{
EDURNE BARTOLOMÉ-PERAL and LLUIS COROMINA** \\ University of Deusto, Bilbao, University of Girona
}

\begin{abstract}
Fundamental aspects of human existence such as birth and death are at the core of our values and profoundly sensitive to our religious beliefs, our ideals as a society, and our opinions on the extent to which individuals may interfere in these basic life issues. This article analyses the factors that explain people's attitudes towards key beginning- and end-of-life issues. To do this, we first tracked variations across two points in time, and then looked at the effects of value orientations and socio-demographic factors in comparative perspective across countries. Based on previous literature, we consider justification for euthanasia, abortion, and in vitro fertilisation as a latent variable using European Value Study data from the 2008 and 2017 waves. Five European societies were analysed: Spain, Germany, the Netherlands, the Czech Republic, and Russia. All the countries observed showed growing levels of justification for these practices, although significant differences were found in the value orientation effects and respondents' background variables on attitudes towards life and death issues. In order to properly address comparability, multi-group confirmatory factor analyses across countries and across waves were conducted, and measurement invariance tested. From our analyses, we can conclude that age and religiosity, alongside other sociodemographic variables, are important explanatory factors in the justification of life and death issues in all the countries examined; however, value orientations show less conclusive effects on such attitudes.
\end{abstract}

Keywords: life and death issues, euthanasia, abortion, in-vitro fertilisation, values

Sociologický časopis/Czech Sociological Review, 2020, Vol. 56, No. 6: 835-862

https://doi.org/10.13060/csr.2020.052

\footnotetext{
* This work was supported by the Spanish Ministry of Science and Innovation under Grant PID2019-106882RB-I00 and by the DFG-German Research Foundation under Grant BE 4267 / 2-1.

** Direct all correspondence to: Edurne Bartolomé-Peral, University of Deusto, Avenido de las Universidades 24, 48007 Bilbao, Spain, e-mail: edurne.bartolome@deusto.es; Lluis Coromina, University of Girona, Carrer de Girona 161, 17820 Girona, Spain, e-mail: 1luis. coromina@udg.edu.
}

(C) Sociologický ústav AV ČR, v. v. i., Praha 2020 


\section{Introduction}

In recent decades, science and technology have advanced in seemingly unstoppable ways. Advances in medicine have enabled us to challenge important human limitations or extend our lifespan. Life's beginning and end mark the human condition and are at the core of universal, existential reflections on the meaning of human life. Birth and death are socially embedded events and therefore subject to social norms, value orientations, and moral views on what a good birth and a good death mean [Dworkin 1993; Emanuel and Emanuel 1998; Long 2001]. Moreover, given that an individual's views on life and death often depend on their religious beliefs, this progress challenges our deepest moral and religious values. According to Lizza [2009: 546], '[j] ust as we can now live in ways that were previously impossible, we can now die in new ways that are made possible by medical technology'.

Beginning- and end-of-life issues have traditionally been a focus of interest for disciplines such as philosophy, ethics, theology, and law. From a social science perspective, the approach has focused more on researching individual attitudes towards boundary situations, and how these crucial situations related to birth and death are articulated and justified, both on a personal level and across social groups. In the literature [Hendry et al. 2013; Howe 2011: 173; Lizza 2009], beginning- and end-of-life issues have been understood as those aspects that theoretically and empirically address the so-called 'present problems of great importance awaiting solution'. From this perspective, beginning and end-of-life issues [Kaufman and Morgan 2005] raise questions about the situation of the unborn and the dying, and about how social contexts make sense of these situations by analysing the actors involved, people's attitudes, government policies, and developments [James 2000; Malpas et al. 2014] in these boundary questions on birth and death (assisted reproduction, abortion, euthanasia). The issues represent a value domain in which citizens feel particularly sensitive about interference in the natural and/or sacred processes of birth and death [Rudnev and Savelkaeva 2018], and attitudes vary significantly across religious denominations and national welfare systems. Western societies are showing a growing interest in beginning- and endof life issues, mainly due to significant shifts in demographic trends linked to increasing life expectancy and postponement of parenthood. Therefore, 'beginning- and end-of-life issues' refer to all moral considerations, value orientations, and norms that exist within social and cultural contexts and are linked to the general public's social and moral attitudes towards fundamental issues surrounding birth and death.

Topics such as euthanasia, abortion, and fertility can be the source of deep controversy among citizens, and regulations on these practices have monopolised intense discussions in the political arena [Fink 2008]. This is an area that relates to our deepest moral codes and values [Ekland-Olson 2014] and one in which the value of autonomy is contrasted with a vision of God's absolute control over life and death [Burdette, Hill and Moulton 2005: 80]. Following from previous defini- 
tions of life and death issues, we consider these three practices to be at the core of our concept and analysis. This article contributes to the literature by empirically analysing issues that have been addressed separately to date.

Science and technology have made significant advances in extending life, reducing suffering, and assisting infertility. Common important life processes that relate to life, birth control, ageing, and death (in which humans have traditionally had little or no capacity to intervene) have been medicalised [Conrad 2007]; this, however, may clash with people's deepest value codes.

These attitudes vary across European societies [Halman and Van Ingen 2015; van Herk and Poortinga 2012; Finke and Adamczyk 2008] and are firmly tied to religious and moral values. Processes such as secularisation and modernisation are at the core of transformations in people's positions on value domains [Inglehart 1997; Inglehart and Baker 2000; Inglehart and Welzel 2005] and are of particular relevance in research on attitudes towards beginning- and end-of-life issues. Secularisation is a highly controversial process of societal change [Halman and Van Ingen 2015], and the consensus on the connection between religion and morality has also been theoretically contested. Many of our moral standards come from religious doctrine; thus, institutionalised religions teach and share moral messages [Uslaner 1999]. The moral compass that religious doctrine provides means that people who are devout tend to be more reluctant to accept practices such as abortion or euthanasia.

However, according to these authors, religious practice has experienced a fundamental shift. If religion provides a normative framework of personal positions on moral questions, as a consequence of secularisation, then moral issues increasingly become a subject of personal choice, rather than being mandated by religious or secular authorities. Declining levels of religiosity as a result of secularisation may therefore have far-reaching consequences for the moral order within societies [Rudnev and Savelkaeva 2018]. Knowing that Europeans are increasingly permissive on moral issues such as homosexuality, abortion, and euthanasia, it could be argued that this increasing permissiveness in people's moral attitudes is linked to the decline in the role of churches in secularised societies, where religious doctrine and moral guidelines are less respected [Halman and Van Ingen 2015].

Value change on fundamental moral issues that relate to life and death also occur as a result of processes of modernisation and post-modernisation [Inglehart 1997; Inglehart and Baker 2000; Inglehart and Welzel 2005]. During the modernisation process, the normative role of morality imposed by traditional religious confessions declined, leading to extensive criticism of religious statements and doctrine and more liberal views on morality issues. As a consequence of modernisation and secularisation, a value change towards secular-rational values has taken place, and religious authorities and doctrine are no longer the only regulator of life and death issues [Halman and Van Ingen 2015]. As a consequence of post-modernisation, values have moved towards self-expression and a growing 
Sociologický časopis/Czech Sociological Review, 2020, Vol. 56, No. 6

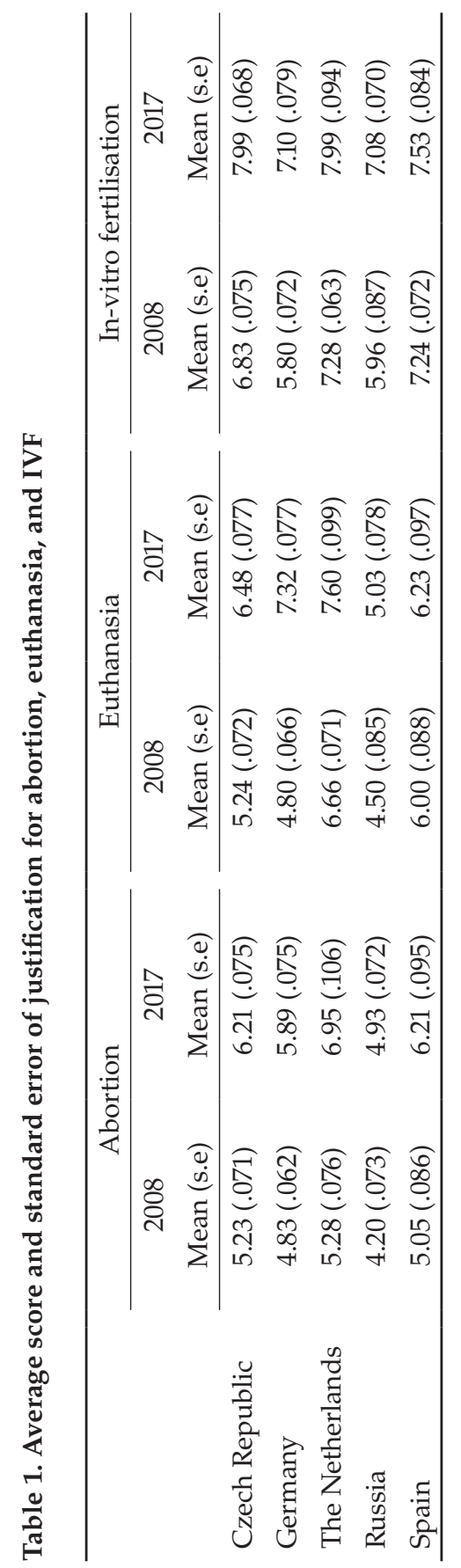


emphasis on personal autonomy and well-being. In relation to euthanasia, Rudnev and Savelkaeva [2018] point out that the improvement of existential security in recent decades has led to more significance being given to the values of autonomy and personal well-being. Regarding end-of-life issues, this improvement in material conditions has triggered a shift in the way we see and understand life, and the emphasis on 'quantity' of life has moved towards 'quality' of life. This change is rooted in autonomy and personal well-being.

The first aim of this study was to analyse attitudes towards key beginningand end-of-life issues by tracking relevant differences across countries and different time periods. For this purpose, a latent variable, namely 'attitudes to beginning- and end-of-life issues', was created to reflect the rationale behind attitudes towards euthanasia, abortion, and in-vitro fertilisation (IVF). The main aim of the study was to explore whether attitudes towards beginning- and end-of-life issues are comparable across countries as a meaningful construct, and how these attitudes evolve over time. The second aim of this research was to analyse the effects of key value orientations and sociodemographic determinants on latent variable attitudes towards beginning- and end-of-life issues, across countries and over time. The data used are from the 2008 and 2017 waves of the European Value Study for five European countries: Spain, Germany, the Netherlands, the Czech Republic, and Russia. For the purpose of the analyses, multi-group confirmatory factor analysis (MGCFA) was conducted across countries and waves, and measurement invariance was tested.

Table 1 shows the average scores for the countries analysed in the last two European Values Study waves, namely 2008 and 2017. Only these two rounds were used in the analysis as earlier waves did not contain all three variables for comparison. These data were used to describe the trend for the single variables on abortion, euthanasia, and in-vitro fertilisation (IVF). These variables are measured on a continuous 10-point scale ranging from 1 (never justified) to 10 (always justified). The data show a uniform rise in the level of justification for abortion, euthanasia, and IVF in all five countries, although there are visible cross-country differences.

This article is structured as follows. First, we present the major contextual factors and transformations affecting personal positions on euthanasia, abortion, and IVF. Second, a revision and explanation of personal-level factors from the literature is set out alongside descriptions of citizens' positions on these issues, and we outline our working hypotheses. Third, we outline the data and methods we used, followed by the data analysis and a discussion of the results. Finally, we present the main conclusions. 


\section{What contextual factors shape personal attitudes towards life and death issues?}

A considerable body of literature exists on the attitudes and determinants of justification for abortion, euthanasia, and IVF [Burdette, Hill and Moulton 2005; Cicirelli 1997; Cohen 2004; Cohen et al. 2006a, 2006b; Cohen et al. 2014; Dierickx et al. 2020; Fink 2008; Gray 2017; Halman and Van Ingen 2015; Jelen and Wilcox 2003; Kemmelmeier et al. 2002; Köneke 2014; Lee 2014; Rudnev and Savelkaeva 2018; Sigillo, Miller and Weiser 2012; Soini et al. 2006; Turner 1997; Verbakel and Jaspers 2010]. These studies have analysed the determinants of attitudes towards life and death issues and have offered concurring views on several contextual explanations for personal attitudes. Religious tradition and welfare provisions are found at the core of these attitudes [Cohen et al. 2006a, 2006b, 2014; EspingAndersen 1990, 1996; Halman and Van Ingen 2015; van Herk and Poortinga 2012]. Halman and Van Ingen [2015] highlighted that the process of secularisation is at the core of transformations in attitudes, while Cohen et al. [2006a, 2006b, 2014] and van Herk and Poortinga [2012] point out the influence of religious traditions. The importance of religious denominations on attitudes to moral issues has been widely addressed in the literature. Regarding attitudes towards euthanasia, Cohen et al. [2006a, 2006b] claim that although the influence of religion is highly country-dependent, religious denomination still has a relevant impact on morality issues. Evidence shows that, in general terms, Protestants appear to support euthanasia more than Catholics, the Orthodox Church, or Muslims [Cohen et al. 2014: 150]. These authors support this difference by highlighting that Protestant institutions and communities have failed to uniformly define euthanasia as sinful (in contrast to other denominations). Some faith communities in Protestant Christianity may support this way of dying in specific cases where one of their immediate community is suffering from a terminal illness [Cohen et al. 2006a: 752]. Verbakel and Jaspers [2010] also provide evidence that people who are religious are more opposed to euthanasia. Regarding the effect of denominations, they claim that despite the difference between liberal and evangelical Protestants, they still constitute the most permissive religious group.

With respect to attitudes towards abortion, Lee [2014], and Jelen and Wilcox [2003] have also found evidence that Roman Catholics and evangelical Protestants are well-known to be against abortion. Regarding attitudes towards in vitro fertilisation, similar evidence has been found. Sigillo et al. [2012: 251] provide evidence on the relationship between religious belief and attitudes towards IVF. According to their research, the Catholic Church's position on IVF is that life begins at conception and embryos have the same dignity as any other human being. It therefore condemns these practices, believing that it is a laboratory intervening in life issues that only God, and not a scientist, should control. Like previous research on the impact of denomination on morality issues, the Catholic Church concludes that conservative Protestants are more aligned with Catholics and that liberal Protestants are more willing to accept IVF. Orthodoxy has been described as being consistent with the vision of the Catholic Church [Randolph-Seng et al. 2008]. 
Dierickx et al. [2020] and Cohen [2006a, 2014] have stressed the relevance of the existing legal status of these practices. According to Dierickx et al. (2020), euthanasia is legal in Switzerland, Belgium, the Netherlands, Luxembourg, some states in the USA, and some provinces in Canada, and the legal framework is a clear determinant of what position people take on these issues. Arguing that welfare systems and provisions affect personal orientations, Soini et al. [2006] moreover linked welfare provisions to health-care institutions and institutional trust.

Hyne [2015] emphasises the relevance of policy diffusion and its effect on the formation of attitudes through the socialisation of such practices in daily life. Conversely, health-care institutions in some countries are controlled by religious organisations which determine the actual practices and influence attitudes. Halman and Van Ingen [2015] and van Herk and Poortinga [2012] also provide explanations for differences in attitudes across regions in Europe, such as the prevailing values in these regions, the effect of secularisation, or the influence the communist legacy has on forming beliefs and attitudes.

\section{Individual factors influencing attitudes towards euthanasia, abortion, and IVF}

Contextual aspects such as secularisation, welfare provisions, and legal frameworks are seen as important factors in explaining people's attitudes towards life and death issues. However, the extant literature identifies highly relevant individual-level factors in shaping attitudes. While a number of these factors influence life and death issues separately, namely determinants of attitudes towards euthanasia, abortion, and IVF, we can nonetheless identify common underlying elements that theoretically explain what factors affect life and death issues.

One of the principal factors alluded to in the literature is that of religious denomination and religiosity. According to Jelen and Wilcox [2003], Sigillo, Miller and Weiser [2012], and Cohen [2014], among others, denomination is an important predictor of attitudes towards beginning- and end-of-life issues. As mentioned above, Catholic values, as well as those of the Orthodox Church and Islam, are more unaccepting of issues such as euthanasia and abortion. In contrast, the Protestant religion is generally more permissive [Burdette, Hill and Moulton 2005; Cohen et al. 2014; Sigillo, Miller and Weiser 2012]. More strongly than denomination, it is the level of religiosity that shapes attitudes. Halman and Van Ingen [2015] reflected on the impact of secularisation and the declining importance of religion and church attendance on attitudes towards euthanasia, abortion, and IVF. Higher levels of religiosity are associated with more traditional positions on moral issues, and favour religious arguments over scientific ones regarding beginning- and end-of-life issues [Hyne 2015; Jelen and Wilcox 2003; Lee 2014; Rudnev and Savelkaeva 2018; Sigillo, Miller and Weiser 2012]. Individuals hold profound beliefs about where religious and moral decisions on crucial issues should be made. 
Values are also an important determinant of attitudes to life and death issues. According to Rudnev and Savelkaeva [2018: 304], modernisation has brought about a decline in the relevance of traditional religiosity, while other values have increased in prominence alongside the growing importance of individual choice and self-expression. Personal choice, therefore, has come to take precedence over religious authority or mandates [Kemmelmeier et al. 2002]. In this regard, stronger post-materialist and secular-rational values are a major influence on the growing permissiveness towards life and death issues, in part because of the higher value placed on autonomy over life decisions [Turner 1997]. Rudnev and Savalkaeva [2018: 309] refer to the 'slippery slope hypothesis', understood as those cognitive and material resources which foster feelings of control and decrease feelings of vulnerability when confronted with the system. These include interpersonal trust, and feeling in control over one's life or education [Keown 1992; Verbakel and Jaspers 2010]. Verbakel and Jaspers [2010: 118], also link 'the feeling that one has no real control ... or has complete freedom of choice and control over the way his or her life turns out' to the slippery slope argument, which for their particular study on euthanasia predicts that 'people from nonvulnerable groups are less likely to fear potential abuse of euthanasia, and therefore, have more favourable attitudes toward it'. Therefore, feeling in control of one's life a relevant factor that shapes people's views on life and death issues, in that people believe individuals have complete control over their lives and, ultimately, it is their decision to act on such matters. Conversely, others believe that only God or fate can make decisions at the deepest level of life domains, and that individual decisions should be dependent on the will of a higher power.

Social and institutional trust are also relevant in explaining attitudes towards life and death [Salloch et al. 2015]. Regarding attitudes towards euthanasia, Köneke [2014] and Keown [1992] also associate trust with the 'slippery slope' argument. What this refers to is that individuals who feel vulnerable within institutions and government systems tend to justify euthanasia less. This means that those with higher levels of social and institutional trust in health-care systems have less fear of institutional abuse and malpractice. As Verbakel and Jaspers [2010] state, those who believe in the system's responsiveness also tend to have more positive attitudes towards euthanasia. Here, the 'slippery slope' argument means that accepting euthanasia, even if it could at times be positive or beneficial, may also lead to unwanted and unacceptable consequences.

Age is another important individual factor that can operate in favour of the 'slippery slope' argument in that older people who were socialised at a time when material and medical conditions were poor tend to feel more vulnerable and distrusting; therefore, they may be more fearful of euthanasia [Verbakel and Jaspers 2010]. Age and its effects are widely used to analyse the formation of attitudes to life and death issues [Cicirelli 1997; Cohen et al. 2006a, 2006b, 2014; Dobewall, Tormos and Vauclair 2017; Hyne 2015; Inglehart and Welzel 2005; Jelen and Wilcox 2003; van Herk and Poortinga 2012]. When analysing the changing effect of values or symbolic attitudes over time, it is important to disentangle the effects that time 
period, age, and cohorts may have, which often appear intertwined in the data, even though they are easily distinguished, both conceptually and in terms of their theoretical implications [Tormos 2019: 83]. Various studies have used age cohorts to measure the extent to which members of a given age group who share common features and characteristics have different attitudes towards morality issues, even though they have similar socialisation patterns or experienced the same specific socio-historical events during their 'formative years' [Dobewall, Tormos and Vauclair 2017; Inglehart and Welzel 2005]. Age effects are also highly significant. They can be linked to changes in the life course, the ageing process, the acquisition of personal experiences, and in people's roles and status over their lifetime. The consequent loss of physical and adaptive capacities linked with ageing is a relevant factor for attitudes towards end of life, and so are decisions about delaying parenthood in the light of economic, occupational, and career circumstances. Several authors, such as Cohen et al. [2006b, 2006a, 2014], Sigillo, Miller and Weiser [2012], and Cicirelli [1997], among others, have alluded to age as being a major correlate for attitudes towards end-of-life issues. Regarding IVF and fertility issues, studies on how age impacts individual attitudes towards IVF are scarce, although some studies on attitudes towards embryonic research and embryo transfer exist [Sigillo, Miller and Weiser 2012]. Despite the mixed evidence that has been found on attitudes to embryonic stem cell research, it appears that younger cohorts are more disapproving of this [Sullivan 1993], and Sigillo et al. [2012] have found that younger women may be more disapproving of IVF practices than older women.

Education is also deemed a relevant factor as it acts as a proxy for autonomy and cognitive mobilisation [Jelen and Wilcox 2003; Lee 2014; Verbakel and Jaspers 2010] and is seen as a crucial explanatory factor in attitudes towards abortion and IVF. Other important factors affecting attitudes towards life and death issues are social status and income. Income (a proxy for social status) is particularly relevant when explaining attitudes towards euthanasia [Cicirelli 1997; Cohen et al. 2006a, 2006b, 2014] as it weakens the 'slippery slope' and perceptions of vulnerability [Rudnev and Savelkaeva 2018]. The sex of respondents participating in the study has been included as a control variable.

Several European countries were selected for our analysis. As Verbakel and Jaspers [2010: 111] note, 'despite the huge differences amongst countries ..., existing literature has largely neglected a country-comparative perspective, focusing mainly on individual difference'. Regarding policy stances and the role of religion, Fink [2008] claims that legislation on IVF is stricter in Catholic societies and that the Catholic Church is an influential player. Countries with strong Christian democratic parties also have more restrictive embryo research policies. The levels of permissiveness and availability of resources regarding artificial reproduction techniques vary across countries. For instance, Spain and the Czech Republic are both Catholic countries and important destinations for couples searching for affordable fertility treatment [Dostál 2011; Pennings 2004]. The Netherlands (mixed Catholic and Protestant) also shows high levels of permissiveness, whereas Germany, which is also mixed, has more restrictive views [Busardò et al. 2014; Ory 
et al. 2013]. In terms of levels of permissiveness towards euthanasia, we also find significant variations across Europe. According to EVS data, the general level of permissiveness towards euthanasia among the public is high in the Netherlands and Spain, but levels in Germany and the Russian Federation are lower. This suggests that other country-level factors might be operating beyond the influence of religion [de Moor 1995]. According to Cohen et al. [2014], people living in societies where a person's right to self-determination is accepted at a societal level are more willing to accept these practices regardless of their religion. It is also important to capture the East-West divide [Hildebrandt 2015; Hyne 2015]. The polarisation between Western and Eastern Europe may exist because of drastic socio-economic and political changes after 1989. Mishler and Rose [2007] found that lifelong learning is important for post-communist societies because they have had to adapt to a new world. Countries belonging to geographical regions with similar socio-economic and political histories should therefore show similar trajectories [Dobewall, Tormos and Vauclair 2017].

Cohen et al. [2006a: 747] suggest that the selection of countries should be based on their religious cultural backgrounds, history, and patterns of secularisation. In addition, welfare tradition and provisions and social spending are relevant factors to take into consideration (Bleiklie, Goggin and Rothmayr 2004; Ekland-Olson 2014; Knill, Adam and Hurka 2015; Steck et al. 2013]. Five countries were selected for the analyses. These represent the large range of different religious-historical backgrounds, communist and non-communist legacies, and differing government policies and welfare provisions in Europe. The countries in the sample are: the Czech Republic, an example of a Central-Eastern secularised country with a Catholic tradition and a generous and well-developed welfare system; Germany and the Netherlands, representing Western, pluralistic, secularised countries, but ones that have different welfare state systems and different levels of social and legal permissiveness and offer coverage of both euthanasia and assisted reproduction techniques. Russia represents an Eastern-orthodox country with lower levels of permissiveness towards abortion, euthanasia, and IVF, and it serves as an interesting case to compare with Europe in terms of the differences and similarities in their values. The last country included in the analysis is Spain, a Roman-Catholic Southern European society with a typical Latin welfare system [Cohen et al. 2006a]. This selection of countries covers the different European regions and the main religious traditions, policy stances, and types of welfare state provisions and regulations, particularly regarding all three practices included in the latent dependent variable. As the analyses require measurement invariance, a selection of countries is needed in order to obtain comparable results. However, only a limited number of units can be included, as widening the selection to encompass more countries could lead to non-invariance in some groups, which would have to be excluded from the analyses because of the lack of comparability. The decision to select a small number of countries for the study was made following the theoretical arguments explained above. 


\section{Hypotheses}

Based on a systematic analysis of the theory and literature on the trends and factors that influence views on beginning- and end-of-life issues, we formulate the following hypotheses:

H1: Differences are expected across the five European societies in different years and levels of justification for these practices. In this respect, the level of secularisation, the given religious tradition, and the effect of modernisation in the country are expected to present variations in attitudes towards life and death issues over time due to the lasting effects of these factors.

H2: We expect age effects on attitudes towards birth and death due to the ageing process and life-cycle effects. As mentioned, the effect of age on attitudes is due to the 'slippery slope' argument and to the effects of ageing and alterations of the physical and adaptive capacities linked with ageing. Therefore, it is expected that older generations will be less permissive towards beginning- and endof-life decisions.

H3: The level of religiosity and the importance of religion will have an important impact on attitudes towards beginning- and end-of-life issues. Religiosity and the importance of religion in influencing people's views towards intervention in life and death matters is a widely shared finding in the literature. A higher level of religiosity is associated with more conservative, traditional views regarding the role individuals play in making crucial decisions related to beginning- and end-of-life issues.

H4: We expect that factors such as level of education and income will also have significant effects on beginning- and end-of-life attitudes. It is expected that a higher education level and higher economic status will be associated with more permissive views towards beginning- and end-of-life issues. Education and economic status are expected to increase perception and autonomy and, therefore, weaken the 'slippery slope' and vulnerability arguments. Moreover, feelings of control over life would also tend to weaken the 'slippery slope' and vulnerability.

H5: Secular-rational vs traditional values are expected to have a strong effect on the justification of these practices [Inglehart 1997]. Modernisation and post-modernisation and the consequent change in values they produced have triggered a process whereby beliefs are individualised, reducing the power of a traditional authority to dictate individual choices. Higher levels of security and stability result in more emphasis on autonomy and choice. The present study, therefore, considers post-materialism as a proxy for values of autonomy [Rudnev and Savelkaeva 2018; Verbakel and Jaspers 2010]. 
Table 2. Sample size for each country and period

\begin{tabular}{lrr}
\hline & 2008 & 2017 \\
\hline Czech Republic & 1785 & 1759 \\
Germany & 2070 & 1489 \\
The Netherlands & 1552 & 684 \\
Russia & 1473 & 1799 \\
Spain & 1487 & 1201 \\
\hline
\end{tabular}

\section{Data and methods}

\section{Data}

Table 2 shows the size of the samples of the five countries studied (Czech Republic, Germany, The Netherlands, Russia. and Spain) in 2008 and 2017. The total sample comprises 15299 cases and uses data from the European Values Study for both periods.

By using two waves, we aim to capture the evolution of attitudes over time and to provide deeper insights into the influence of age cohorts on these attitudes, thus offering a wider perspective of the effect of socialisation and changes in values. The method allows us to compare the countries and waves and split ages into cohorts to obtain a more detailed picture of the effect each age group has on attitudes over time.

\section{Method}

The study measures 'attitudes towards beginning- and end-of-life' as a latent factor $\left(\eta_{j}\right)$, with three reflective indicators, using confirmatory factor analysis (CFA). Brown [2015] showed a generalised path diagram (Figure 1), where ' $\kappa$ ' represents the latent mean for the construct; $\mathrm{y}_{1}=$ abortion, $\mathrm{y}_{2}=$ euthanasia, $\mathrm{y}_{3}=$ in-vitro fertilisation; $\lambda_{1 j^{\prime}} \lambda_{2 j^{\prime}}$ and $\lambda_{3 j}$ are the factor loadings on the items $y_{1^{\prime}}, y_{2^{\prime}}$ and $y_{3}$ (see Figure 2 for the variables used).

The three indicators obtained from the European Values Study were measured using responses to a question on a 10-point scale: 'Please tell me for each of the following actions whether you think it can always be justified (10), never be justified (1), or something in between'. The specific justifications analysed are 'euthanasia', 'abortion', and 'in vitro fertilisation'.

The CFA model was analysed for the different countries and years, and multiple group confirmatory factor analysis (MGCFA) was used to compare the different groups. Using MGCFA [Bollen 1989; Byrne 2012; Davidov et al. 2014] not 
Figure 1. Composition of the latent variable

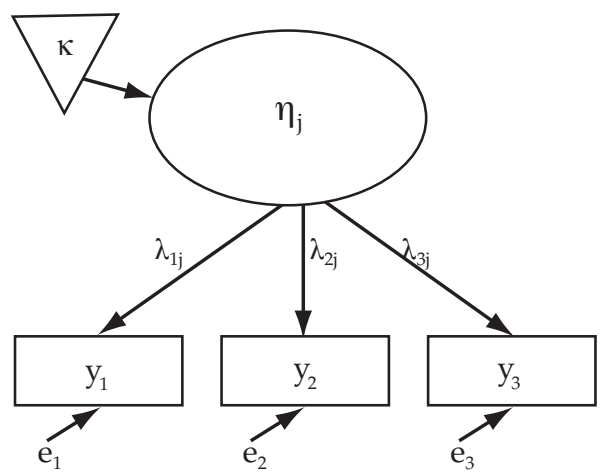

Figure 2. Theoretical CFA model used

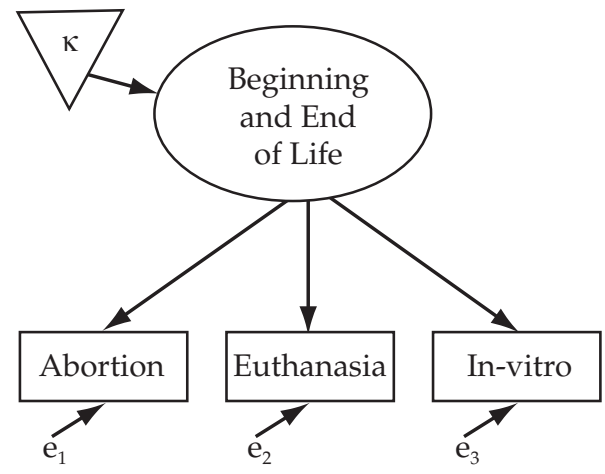

only ensures that the results will be accurate, it also introduces flexibility into the estimation models, thus producing more accurate estimates of the relationships between the theoretically related variables and the latent factor of interest, while taking measurement error into account. MGCFA is generally used for cross-cultural comparisons when testing whether a latent variable or construct of interest is comparable across groups.

Measurement invariance is needed to make comparisons between groups and to explain meaningful comparisons. Since one of the objectives of the study was to detect the effect of predictor variables on the model, invariance ensured that meaning and scaling would be equal across groups. Depending on the level of invariance, different typologies of comparison can be carried out. Generally, three hierarchical levels of measurement invariance are tested: configural, met- 
ric, and scalar [Davidov et al. 2014; Milfont and Fischer 2010]. Configural invariance is the least strict of the three, followed by metric and scalar invariance, the most restrictive, where it is required that metric and scalar invariance be tested. It requires the same path diagram among groups, while the values for the loadings and intercepts can differ between the groups. Thus, if this invariance holds, it enables comparisons of the model structure, but not comparisons of relationships between variables or latent means across groups. Metric invariance requires equal loadings for each group; if the invariance holds, it permits relationship comparisons. Scalar invariance, which requires equal loadings and intercepts among groups, is stricter than metric invariance; if the scalar invariance holds, the comparisons of latent means between groups are meaningful [Ariely and Davidov 2012; Davidov et al. 2014].

Finally, the effect of the theoretically studied factors on the latent variable 'attitudes towards beginning- and end-of-life' was examined, and multiple group structural equation modelling (MGSEM) was carried out in order to identify significant predictive variables on the latent variable in the different countries (Czech Republic, Germany, the Netherlands, Russia and Spain) in two time periods (2008 and 2017).

\section{Measurement of the variables}

The operationalisation of the predictive variables was presented and grouped according to theoretical dimensions presented in the literature. All the variables were taken from the 2008 and 2017 waves of the European Values Study.

The level of religiosity was measured through the self-assessment variable on the level of religiosity and trust in the church as an institution, as stated below.

- Religious. 'Are you a religious person?' Measurement: Coded as 1 for a religious person and 0 for a person who is not religious or an atheist.

- Confidence in the church. 'Please look at this card and for each item listed tell me how much confidence you have in the church.' The measurement was reversed from the original scale to be a great deal (4), quite a lot (3), not very much (2), and none at all (1).

As identified in the literature, trust was measured through both of its dimensions: social trust and institutional trust. The variable confidence in the healthcare system was used as a measure of institutional trust and a proxy for the 'slippery slope' argument. Another measure for the 'slippery slope' hypothesis was the variable 'control over one's life', reflecting individuals' perception of how much control they feel they have over important decisions and life happenings [Rudnev and Savelkaeva 2018; Verbakel and Jaspers 2010].

- Social trust: 'Generally speaking, would you say that most people can be trusted or that you need to be very careful when dealing with people?' Measurement: Yes / No. 
- Confidence in the health-care system. 'How much confidence do you have in the health-care system?' Measurement: reversed from the original scale to a great deal (4), quite a lot (3), not very much (2), and none at all (1).

- Control over life. 'Some people feel that they have complete freedom of choice and control over their lives, while others feel that what they do has no real effect on what happens to them. How much freedom of choice and control do you feel you have over the way your life turns out?' Measurement: from 'no choice at all' (1) to a great deal of choice' (10).

The impact of values was measured through the post-materialism index provided by the European Values Study questionnaire and data.

- Materialism - post-materialism. 'People sometimes talk about what the aims of this country should be for the next ten years. This card lists some of the goals different people give top priority. Would you please say which one of these you consider to be the most important: maintaining order in the nation; more say in important government decisions; fighting rising prices; protect freedom of speech.' Measurement: Materialism (maintaining order in nation and fighting rising prices) is coded as 0 and post-materialism (more say in important government decisions and protect freedom of speech) coded as 1.

The socio-demographic and control measures provided are the scale of income, measured measured by a person's self-ranking in a decile table of incomes as a proxy for status. Education was included in the analysis with a measure in nine categories, and four age cohorts were included to capture the generational effects at both moments in time. The respondent's sex was also included as a control variable.

- Scale of income. 'On this card, we would like to know the income group your household belongs to. Please specify the figure, including all wages, salaries, pensions and other income.' Measurement: from the 'lowest income decile' (1) to the 'highest income decile' (10).

- Level of education. 'What is the highest level of educational attainment?' Measurement: from 'no formal education' (1) to 'tertiary education' (9).

- Age. Age, in years.

- Respondent's sex. Measurement: $0=$ female and $1=$ male.

\section{Results}

This section presents the results for the fit of the models, the scores for the latent means, and the effect of the predictor variables on the latent variable in order to identify its importance for the different countries and its trend over time. In order to test comparability among countries and over time, MGCFA was carried out and the model fit and measurement invariance evaluated. To address comparability for the latent means, scalar invariance is required, and metric invariance 
Sociologický časopis/Czech Sociological Review, 2020, Vol. 56, No. 6

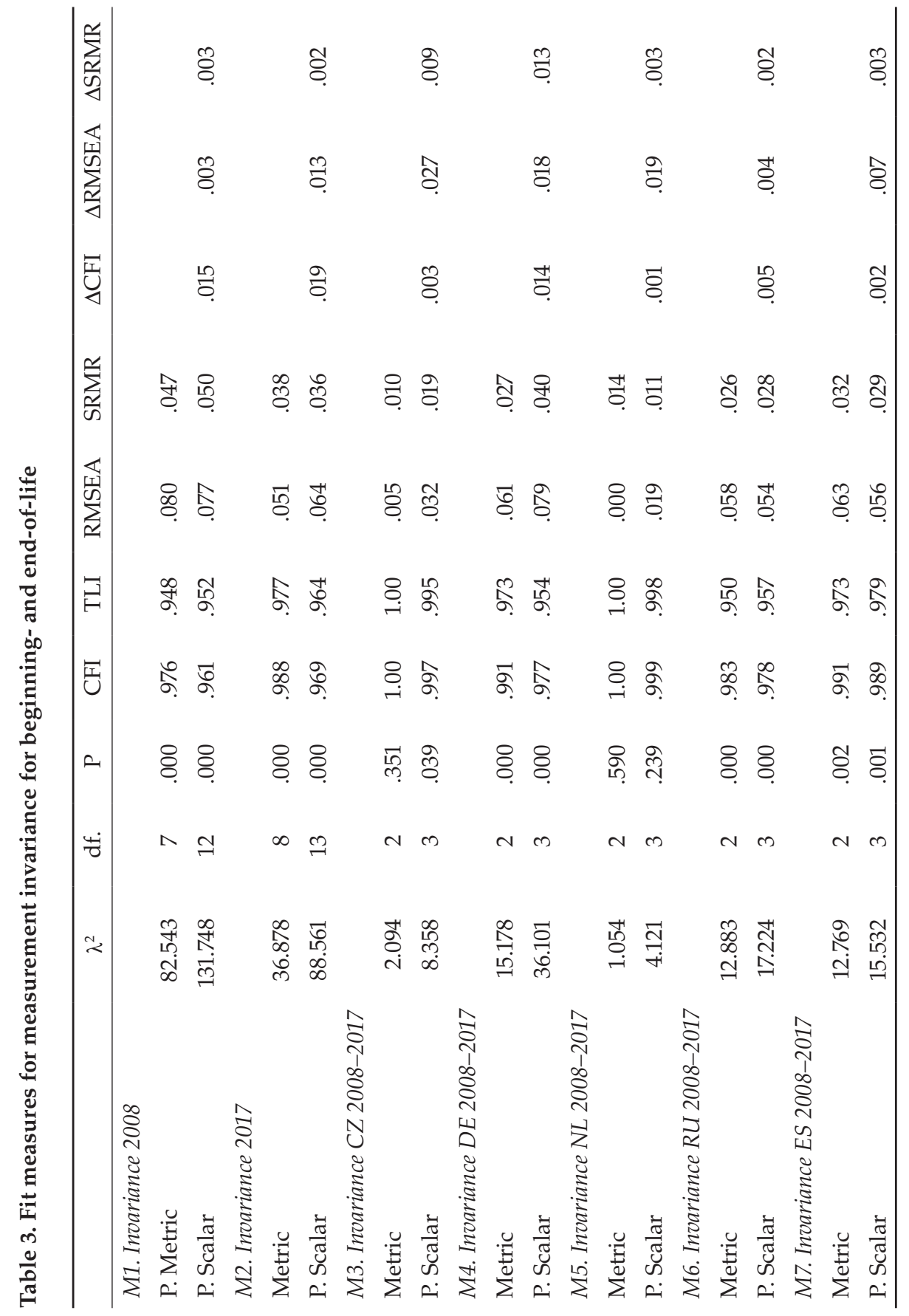


is needed to ensure the comparability of the effects of the predictor variables on the latent variable. Models to evaluate the temporal measurement invariance are assessed using five models within each country, while country invariance is assessed using two models in all countries within each year.

In order to evaluate the model fit, different fit measures were used. The first two criteria used were the standardised root mean square residual (SRMR) and the root mean square error of approximation (RMSEA) measures. SRMR values of 0.08 or lower [Hu and Bentler 1999] and RMSEA values of 0.06 or lower indicate acceptable fit [Chen 2007]. In addition, incremental fit indices, the comparative fit index (CFI), and the Tucker-Lewis index (TLI) were used to calculate improvements in the competing models. Values higher than 0.90 for these two indices indicate an acceptable model fit [Chen 2007]. Some criteria for measurement invariance have been used. Chen [2007] recommended that scalar non-invariance is evidenced by a change in CFI greater than 0.01 , supplemented by a change in RMSEA greater than 0.015 or a change in SRMR greater than 0.01 compared with the metric invariance model.

The model fit displayed in Table 3 shows a satisfactory goodness of fit for the different models.

Metric invariance is found for the different models (except M1 for Germany, which required partial invariance). Partial scalar measurement invariance holds, since some intercepts have been unconstrained in the models (four intercepts for M1, three intercepts for M2, and one intercept for the models M3 to M7). The different model fit indices CFI, TLI, RMSEA, and SRMR are adequate. Model fit indices for the scalar non-invariance show that in the models at least two requirements ( $\triangle$ CFI, $\triangle$ RMSEA, $\triangle$ SRMR) are fulfilled, and the remaining ones are close to the cut-off values. Additionally, when scalar invariance does not hold, alternative tests of partial invariance based on modification indices (MI) can be used [Byrne, Shavelson and Muthén 1989]. After estimating the models and taking into account the modification indices (MI), the expected parameter change (EPC), and the power of the test [Saris, Satorra and van der Veld 2009], no misspecifications were found in the models.

Table 4 shows the latent variables for the different groups. The latent means were not estimated in absolute scores, but rather as an arbitrary 'a-dimensional' factor mean, reflecting average differences in the level of the latent factor across the groups. The latent means in Table 4 were obtained for the different countries in 2008 (model M1) in order to compare them across countries, and then the variation for each country was obtained by estimating models M3 to M7.

Partial measurement invariance may allow appropriate across group comparison under certain circumstances, which is when measurement invariance does not hold [[Byrne, Shavelson and Muthén 1989; Milfont and Fischer 2010], and metric partial invariance or scalar partial invariance holds, but only if the parameters freed across groups are a minority in the model, and the theoretical and empirical bases are also necessary [Vandenberg and Lance 2000]. In that case 
Table 4. Latent factor means and standard errors for tolerant attitudes towards beginning- and end-of-life issues

\begin{tabular}{lccc}
\hline & \multicolumn{3}{c}{ Latent means and s.e. } \\
\cline { 2 - 4 } & 2008 & 2017 & Variation \\
\hline Czech Republic & 0 & 0.480 & +0.480 \\
Germany & -0.315 & 0.293 & +0.608 \\
& $(0.042)$ & $(0.046)$ & \\
The Netherlands & 0.415 & 0.820 & +0.405 \\
& $(0.055)$ & $(0.051)$ & \\
Russia & -0.410 & -0.127 & +0.263 \\
& $(0.041)$ & $(0.047)$ & +0.042 \\
Spain & 0.348 & 0.390 & \\
& $(0.047)$ & $(0.048)$ & \\
\hline
\end{tabular}

the comparisons are meaningful but must be taken with caution [Whisman and Judd 2016; Zercher et al. 2015].

Table 4 shows that the means of the latent variable 'attitudes towards beginning- and end-of-life' increased in all five countries between 2008 and 2017. A clear positive difference can be observed between 2008 and 2017, except in Spain, which showed almost no difference between periods. The Netherlands and Spain had the highest value in 2008, while in 2017 the Netherlands clearly had the highest value, as Spain showed no significant increase.

Thus, the latent means in Table 4 and Figure 3 show an increase in the justification of attitudes towards life and death issues in all five countries; larger increases could be observed in Germany, the Czech Republic, and the Netherlands and smaller increases for Russia, with Spain recording the most marginal increase in attitudes towards of beginning- and end-of-life issues between 2008 and 2017.

Data for 2017 show that citizens in the Netherlands show the highest levels of justification for these issues, followed by the Czech Republic, Spain, Germany, and Russia, where levels remained the lowest. The trend of the latent means and the different levels of justification in the countries prove the first hypothesis on rising levels of justification and permissiveness towards life and death issues in European societies.

In relation to the explanatory analysis, we present the MGSEM results, where the significant predictive variables have an effect on the latent variable 'attitudes towards beginning- and end-of-life'. It is therefore possible to determine the effect of the influential variables on the latent variable. Tables $5 \mathrm{a}$ and $5 \mathrm{~b}$ show the effects of the variables on the dependent latent variable of life and death is- 
Figure 3. Justification of beginning- and end-of-life issues (latent factor means)

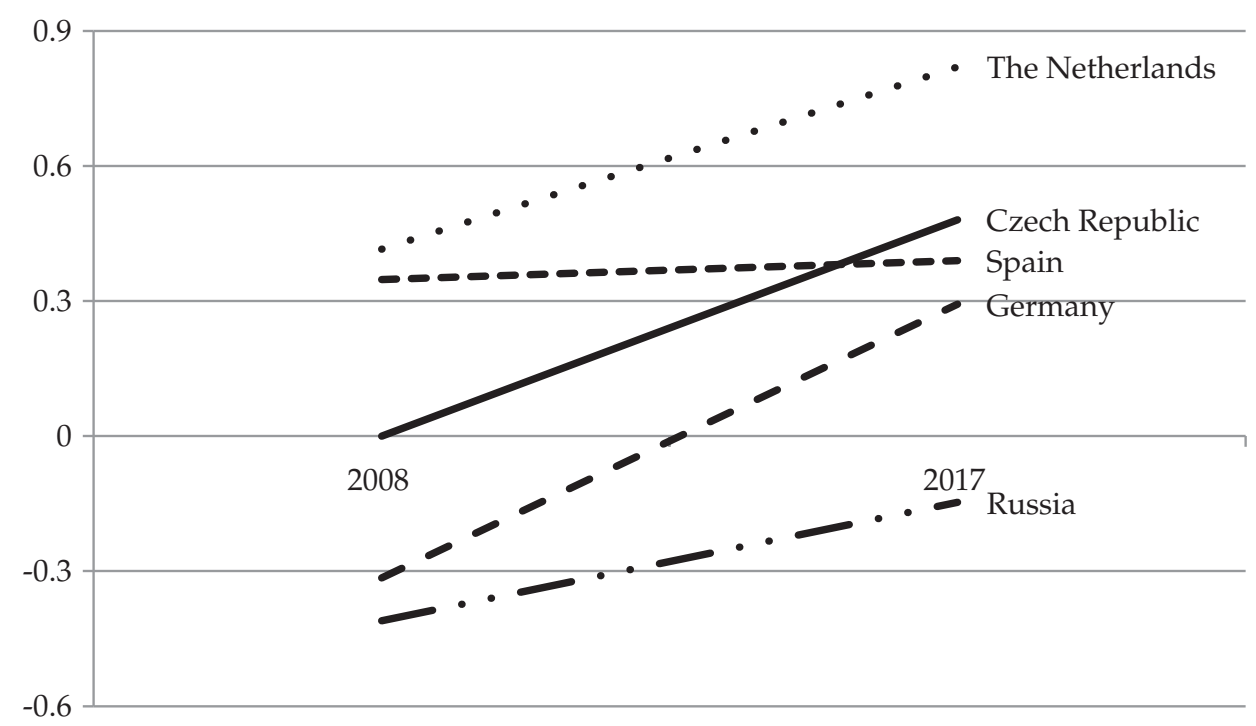

Source: Authors based on EVS 2008 and 2017.

sues identified in the literature. Religiosity is observed to have a negative impact on attitudes towards life and death issues in all the countries and in all years, which is consistent with the theory. The self-assessed level of religiosity had a significant negative effect in all the countries, except in the Czech Republic in both years and in Russia in 2008, while the strongest impact was found in the Netherlands. Religiosity, measured through confidence in the church, has a significantly negative impact in all the countries and periods examined.

The feeling of having control over one's life is a measure that is relevant for the 'slippery slope argument'. This variable had a systematic, positive effect in the Netherlands and Spain in 2008, and in Russia and Czech Republic in 2017; while in Germany the coefficient was negative in 2008 and non-significant in 2017.

The trust variables, however, present mixed results. Interpersonal or social trust has a positive and significant effect on beginning- and end-of-life in Germany, the Netherlands, and Spain, while the Czech Republic had a negative coefficient in 2008 and non-significant effect in 2017, while Russia does not appear to be significantly affected by social trust. Institutional trust, which is measured as confidence in the health-care system, also shows mixed results. As expected, the effects of institutional trust are significant and positive in Spain, while significant negative effects are found in Germany. The effect of institutional trust on the dependent variable in the rest of the countries is non-significant (5\% signifi- 


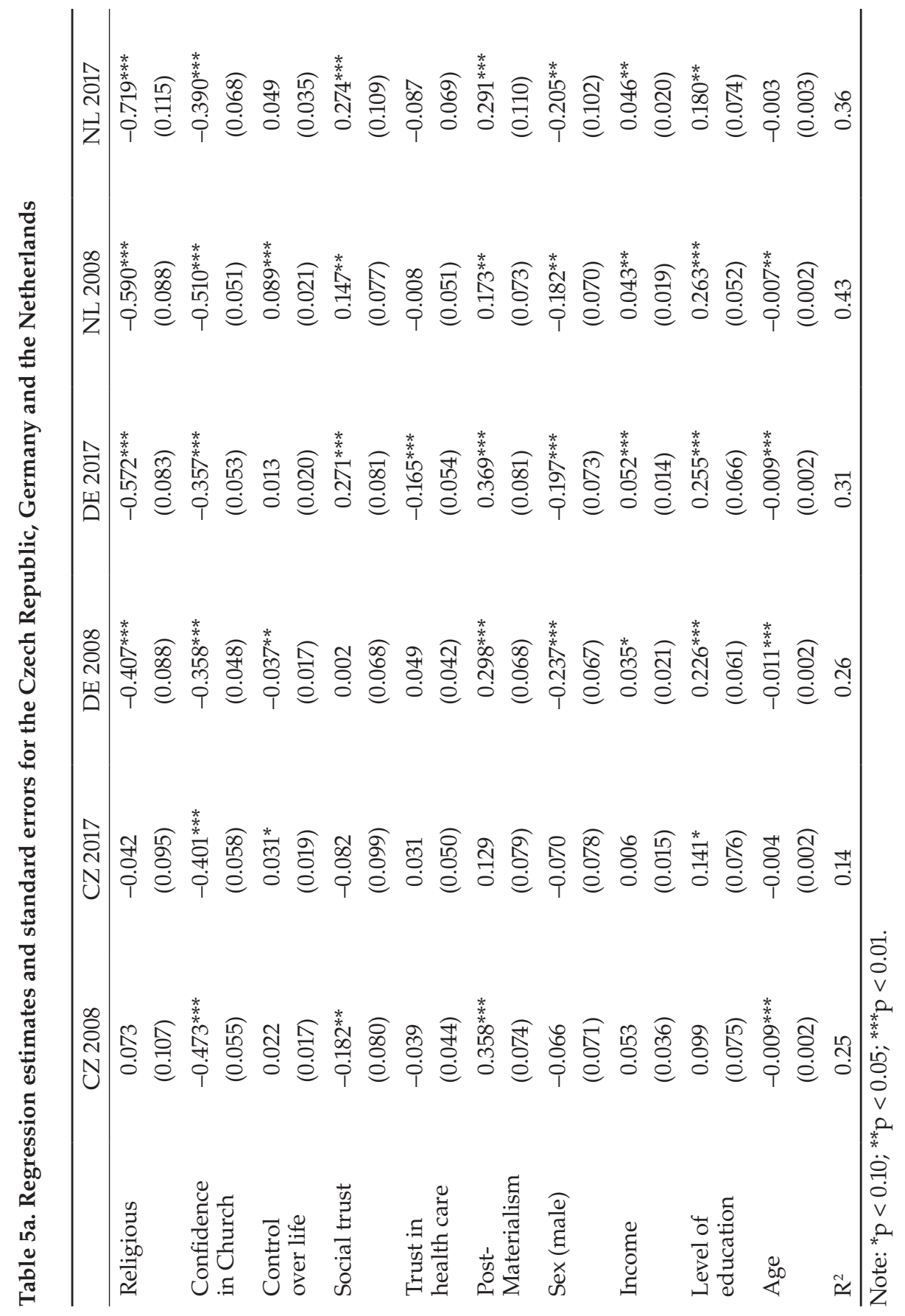


Table 5b: Regression estimates and standard error for Russia and Spain

\begin{tabular}{lcccc}
\hline & RU 2008 & RU 2017 & ES 2008 & ES 2017 \\
\hline Religious & 0.126 & $-0.212^{*}$ & $-0.448^{* * *}$ & $-0.414^{* * *}$ \\
Confidence & $(0.126)$ & $(0.111)$ & $(0.114)$ & $(0.124)$ \\
in Church & $-0.128^{* *}$ & $-0.178^{* * *}$ & $-0.547^{* * *}$ & $-0.498^{* * *}$ \\
Control over & $(0.053)$ & $(0.048)$ & $(0.058)$ & $(0.063)$ \\
life & 0.022 & $0.039^{*}$ & $0.066^{* * *}$ & 0.026 \\
Social trust & $(0.017)$ & $(0.020)$ & $(0.022)$ & $(0.028)$ \\
& -0.049 & 0.036 & $0.202^{* * *}$ & $0.202^{* *}$ \\
Post- & $(0.091)$ & $(0.096)$ & $(0.088)$ & $(0.097)$ \\
Materialism & -0.058 & -0.009 & $0.273^{* * *}$ & $0.316^{* * *}$ \\
Trust in & $(0.119)$ & $(0.091)$ & $(0.089)$ & $(0.097)$ \\
health care & 0.009 & $0.085^{*}$ & -0.077 & $0.210^{* * *}$ \\
& $(0.049)$ & $(0.048)$ & $(0.060)$ & $(0.062)$ \\
Sex (male) & & & & \\
Income & -0.115 & $-0.316^{* * *}$ & $-0.331^{* * *}$ & -0.053 \\
Level of & $(0.100)$ & $(0.084)$ & $(0.084)$ & $(0.095)$ \\
education & $0.152^{* * *}$ & $0.084^{* * *}$ & $0.049^{* * *}$ & 0.030 \\
Age & $(0.054)$ & $(0.018)$ & $(0.018)$ & $(0.018)$ \\
R $^{2}$ & 0.008 & 0.095 & 0.070 & 0.106 \\
\hline Note * & $(0.069)$ & $(0.061)$ & $(0.061)$ & $(0.065)$ \\
& $-0.014^{* * *}$ & $-0.008^{* * *}$ & $-0.013^{* * *}$ & $-0.010^{* * *}$ \\
& $(0.003)$ & $(0.003)$ & $(0.003)$ & $(0.003)$ \\
& 0.10 & 0.16 & 0.46 & 0.40 \\
\hline
\end{tabular}

Note: ${ }^{*} \mathrm{p}<0.10 ;{ }^{* *} \mathrm{p}<0.05 ;{ }^{* * *} \mathrm{p}<0.01$

cance). A possible explanation for these mixed effects relating to trust in health care could be the cross-country differences in welfare provision and individuals' expectations regarding the role they believe health-care institutions should play in life and death issues.

Our analysis also showed mixed results regarding the influence of materialism and post-materialism. Strong positive effects were found in all countries except Russia in both years and in the Czech Republic in 2017, where there were no significant effects. The fact that positive significant effects are stronger in this [2017] wave suggests that the value transformation became more visible in some countries in recent years. The evolution of the effects of materialist and post-ma- 
terialist values on attitudes towards life and death issues across European regions could be a fruitful topic for further research in terms of observing the presence of systematic effects. Other effects, such measuring values in the model show significant effects, such as social and institutional trust, or control over one's life, measuring the slippery slope argument and level of education, as a proxy for cognitive mobilisation and autonomy.

On examining the impact of socio-demographic variables on attitudes towards life and death issues, income, which is used as a measure of status, proved to have a positive systematic effect in the different countries except for Czech Republic, with no significant effects. This confirms the hypothesis that those who are better off tend to be more permissive of the practices analysed. The same effect can be observed for education, which has a positive, quasi-systematic effect in the countries examined except for Spain and Russia. As regards the sex of respondents, we find that males appear to be less permissive than females.

The results show that ageing has a clear negative effect on attitudes towards beginning- and end-of-life, but this effect is slightly weaker in the Netherlands. The evidence suggests that older people are less permissive when it comes to justifying issues surrounding life and death. According to the theory and the 'slippery slope' argument, less permissive attitudes are associated with a higher perception of vulnerability. We have also observed that age affects attitudes towards life and death more strongly in the 2008 wave. This may indicate socialisation effects, where people socialised in more difficult conditions during the Second World War and in the post-war period tend to have less permissive views than older cohorts socialised in an earlier period. Moreover, this might also suggest time period effects, also called effects of 'the times', which reflect the influence of historical contexts irrespective of people's age [Tormos 2019: 83].

Our analyses of attitudes towards life and death issues, which are taken together as a latent variable, reveal significant cross-country differences and increased permissibility over time, as set out in Hypothesis 1. Older cohorts tend to be less permissive when it comes to justifications of life and death issues, which confirms Hypothesis 2. Higher levels of religiosity were still a strong predictor of restrictive attitudes, as suggested by Hypothesis 3 . The effect of education and income was also confirmed by Hypothesis 4 in the majority of the countries studied. For Hypothesis 5, the values related to post-materialism were systematic, although with some exceptions; and in the case of trust, our expectations were only partially confirmed, as we found mixed effects in the countries studied.

\section{Conclusion}

This study examined attitudes towards beginning- and end-of-life issues in a comparative perspective in five European societies. Issues relating to fundamental aspects of life and death such as euthanasia, abortion, and fertility are contro- 
versial and the subject of intense debate within societies and in current political discussions [Fink 2008], as our deepest moral codes and religious and political values influence our judgement of and attitudes towards the extent to which individuals should or should not be able to intervene in life and death. Unlike other studies on the same topics, we took attitudes towards euthanasia, abortion, and IVF as the latent construct and analysed this as the dependent variable. Measurement invariance tests were conducted to address comparability across the countries analysed. Even if our three outcome variables (justification for euthanasia, IVF, and abortion) are seen as being different in nature, and in some contexts respond to similar contextual and personal factors, we addressed attitudes towards these issues as a unique factor. Moreover, we observed that the overall level of permissiveness clearly rose, although cross-country differences were observed in the levels of acceptance and the effect of the independent variables.

Our analysis shows that religiosity and age explained attitudes towards life and death issues most consistently. Other factors such as income or education also had clear effects, but exceptions were observed. From our observation of these effects on our dependent latent variable across the countries examined, we can say that attitudes towards life and death issues are dependent on background variables such as religion, education, age, and income. Values had a clear effect, although the effect was not monolithic over time in the countries analysed. Although there was a clearly positive pattern to the effect of values such as social trust or control over one's life, they were not significant in every country; the effect of post-materialism on the latent variable shows, however, more systematic effects.

This lack of uniformity in the effect values has on attitudes opens up interesting new avenues for further research to find possible explanations. One such explanation is that the attitudes measured in the dependent variable, given their nature, are slowly becoming sensitive to the effect of post-materialist and emancipatory values. Another possible explanation could be the effects of country-level factors that were not contemplated in our analysis. Finally, the composition of our dependent latent variable, even if it clearly constitutes a meaningful theoretical construct, may show some relevant cross-country differences in terms of the effects of the independent variables.

From our analysis of attitudes towards life and death, taken as a latent construct, we found that in the five countries examined the justification for such practices appears to be influenced by background factors such as religiosity, age, education, and income, as they show uniform effects in all the countries analysed. Other factors such as post-materialist values, autonomy-related values and trust are important predictors of attitudes towards life and death; however, the effects they have in the countries examined remain unclear. 
EDURne BARTOlomé-Peral is a lecturer in the Department of International Relations and Humanities at the Faculty of Social and Human Sciences of the University of Deusto (Spain). Her research and publications are primarily devoted to political culture, political values, and attitudes in a comparative perspective, on political support and trust, and on the application of experimental models.

LLUIS COROMINA is an associate professor of quantitative methods at the Faculty of Economics of the University of Girona (Spain). His research focuses on survey methodology, social network analysis and structural equation models for comparative purposes. In recent research he has been examining the quality of survey data measurement. He is a reviewer for international impact journals.

\section{References}

Ariely, G. and E. Davidov. 2012. 'Assessment of Measurement Equivalence with CrossNational And Longitudinal Surveys in Political Science.' European Political Science, 11 (3): 363-377, https://doi.org/10.1057/eps.2011.11.

Bleiklie, I. A., M. L. Goggin and C. Rothmayr. 2004. Comparative Biomedical Policy: Governing Assisted Reproductive Technologies. London: Routledge, https://doi.org/10.4324/9780203358306.

Bollen, K. A. 1989. Structural Equations with Latent Variables. Wiley Series in Probability and Mathematical Statistics. New York: Wiley, https://doi.org/10.1002/9781118619179.

Brown, T. A. 2015. Confirmatory Factor Analysis for Applied Research. Methodology in the Social Sciences. 2nd ed. New York, NY: Guilford Press.

Burdette, A. M., T. D. Hill and B. E. Moulton. 2005. 'Religion and Attitudes toward Physician-Assisted Suicide and Terminal Palliative Care.' Journal for the Scientific Study of Religion, 44 (1): 79-93, https://doi.org/10.1111/j.1468-5906.2005.00266.x.

Busardò, F. P., M. Gulino, S. Napoletano, S. Zaami and P. Frati. 2014. 'The Evolution of Legislation in the Field of Medically Assisted Reproduction and Embryo Stem Cell Research in European Union.' BioMed Research International 2014: 1-14, https://doi.org/10.1155/2014/307160.

Byrne, B. M. 2012. Structural Equation Modeling with Mplus: Basic Concepts, Applications, and Programming. Multivariate Applications Series. New York: Routledge, https://doi.org/10.4324/9780203807644.

Byrne, B. M., R. J. Shavelson and B. Muthén. 1989. 'Testing for the Equivalence of Factor Covariance and Mean Structures: The Issue of Partial Measurement Invariance.' Psychological Bulletin 105 (3): 456, https://doi.org/10.1037/0033-2909.105.3.456.

Chen, F. 2007. 'Sensitivity of Goodness of Fit Indices to Lack of Measurement Invariance.' Structural Equation Modeling: A Multidisciplinary Journal 14 (3): 464-504, https://doi.org/10.1080/10705510701301834.

Cicirelli, V. G. 1997. 'Relationship of Psychosocial and Background Variables to Older Adults' End-of-Life Decisions.' Psychology and Aging 12 (1): 72, https://doi.org/10.1037/0882-7974.12.1.72.

Cohen, J. E. 2004. 'Economic Perceptions and Executive Approval in Comparative Perspective. Political Behavior 26 (1): 27-43, https://doi.org/10.1023/B:POBE.0000022342.58335.cd. 
Cohen, J., I. Marcoux, J. Bilsen, P. Deboosere, G. Van der Wal and L. Deliens. 2006a. 'European Public Acceptance of Euthanasia: Socio-demographic and Cultural Factors Associated with the Acceptance of Euthanasia in 33 European Countries.' Social Science E Medicine 63 (3): 743-756, https://doi.org/10.1016/j.socscimed.2006.01.026.

Cohen, J., I. Marcoux, J. Bilsen, P. Deboosere, G. Van der Wal and L. Deliens. 2006b. 'Trends in Acceptance of Euthanasia among the General Public in 12 European Countries (1981-1999).' The European Journal of Public Health 16 (6): 663-669, https://doi.org/10.1093/eurpub/ckl042.

Cohen, J., P. Van Landeghem, N. Carpentier and L. Deliens. 2014. ‘Public Acceptance of Euthanasia in Europe: A Survey Study in 47 Countries.' International Journal of Public Health 59 (1): 143-156, https://doi.org/10.1007/s00038-013-0461-6.

Conrad, P. 2007. The Medicalization of Society: On the Transformation of Human Conditions into Treatable Disorders. Baltimore, MD: Johns Hopkins University Press.

Davidov, E., B. Meuleman, J. Cieciuch, P. Schmidt and J. Billiet. 2014. 'Measurement Equivalence in Cross-National Research.' Annual Review of Sociology 40 (1): 55-75, https://doi.org/10.1146/annurev-soc-071913-043137.

de Moor, R. A. 1995. Values in Western Societies (Vol. 2). Leiden: Brill.

Dierickx, S., B. Onwuteaka-Philipsen, Y. Penders, J. Cohen, A. van der Heide, M. Puhan, S. Ziegler, G. Bosshard, L. Deliens and K. Chambaere. 2020. 'Commonalities and Differences in Legal Euthanasia and Physician-Assisted Suicide in Three Countries: A Population-Level Comparison.' International Journal of Public Health 65 (1): 65-73, https://doi.org/10.1007/s00038-019-01281-6.

Dobewall, H., R. Tormos and C.-M. Vauclair. 2017. 'Normative Value Change across the Human Life Cycle: Similarities and Differences across Europe.' Journal of Adult Development 24 (4): 263-276, https://doi.org/10.1007/s10804-017-9264-y.

Dostál, J. 2011. 'Specific Ethical and Legal Aspects of ART Practice in Eastern Europe. Pp. 63-86 in Ethical Dilemmas in Assisted Reproduction Techniques, edited by J. G. Schenker. Berlin and Boston: De Gruyter, https://doi.org/10.1515/9783110240214.63.

Dworkin, R. 1993. Life's Dominion: An Argument about Abortion, Euthanasia, and Individual Freedom. New York: Alfred A. Knopf.

Ekland-Olson, S. 2014. Who Lives, Who Dies, Who Decides?: Abortion, Neonatal Care, Assisted Dying, and Capital Punishment. New York and London: Routledge, https://doi.org/10.4324/9781315750453.

Emanuel, E. J. and L. L. Emanuel. 1998. 'The Promise of a Good Death.' The Lancet 351: 21-29, https://doi.org/10.1016/S0140-6736(98)90329-4.

Esping-Andersen, G. 1990. The Three Worlds of Welfare Capitalism. Princeton, NJ: Princeton University Press, https://doi.org/10.1177/095892879100100108.

Esping-Andersen, G. 1996. Welfare States in Transition: National Adaptations in Global Economies. London: Sage.

Fink, S. 2008. 'Politics as Usual or Bringing Religion Back In? The Influence of Parties, Institutions, Economic Interests, and Religion on Embryo Research Laws.' Comparative Political Studies 41 (12): 1631-1656, https://doi.org/10.1177/0010414007309203.

Finke, R. and A. Adamczyk. 2008. 'Cross-national Moral Beliefs: The Influence of National Religious Context.' The Sociological Quarterly 49 (4): 617-652, https://doi.org/10.1111/j.1533-8525.2008.00130.x.

Gray, A. M. 2017. 'Attitudes to Abortion in Northern Ireland.' Research Update 115: 1-8.

Halman, L. and E. Van Ingen. 2015. 'Secularization and Changing Moral Views: European Trends in Church Attendance and Views on Homosexuality, Divorce, Abortion, and Euthanasia.' European Sociological Review 31 (5): 616-627, https://doi.org/10.1093/esr/jcv064. 
Hendry, M., D. Pasterfield, R. Lewis, B. Carter, D. Hodgson and C. Wilkinson. 2013. 'Why Do We Want the Right to Die? A Systematic Review of the International Literature on the Views of Patients, Carers and the Public on Assisted Dying.' Palliative Medicine 27 (1): 13-26, https://doi.org/10.1177/0269216312463623.

Hildebrandt, A. 2015. 'What Shapes Abortion Law? - A Global Perspective.' Global Policy 6 (4): 418-428, https://doi.org/10.1111/1758-5899.12208.

Howe, E. G. 2011. 'Defining the Beginning and End of Life: Readings on Personal Identity and Bioethics, edited by John P Lizza.' Psychiatry 74 (2): 172-182, https://doi.org/10.1521/psyc.2011.74.2.172.

Hu, L. and P. M. Bentler. 1999. 'Cutoff Criteria for Fit Indexes in Covariance Structure Analysis: Conventional Criteria versus New Alternatives.' Structural Equation Modeling: A Multidisciplinary Journal 6 (1): 1-55, https://doi.org/10.1080/10705519909540118.

Hyne, J. 2015. 'Region, Rights and Religion: Cross-national Determinants of Abortion Laws.' Student Paper Series 22. Barcelona: IBIA.

Inglehart, R. 1997. Modernization and Postmodernization. Cultural, Economic and Political Change in 43 Societies. Princeton, NJ: Princeton University Press.

Inglehart, R. and W. E. Baker. 2000. 'Modernization, Cultural Change, and the Persistence of Traditional Values.' American Sociological Review 65 (1): 19-51, https://doi.org/10.2307/2657288.

Inglehart, R. and C. Welzel. 2005. Modernization, Cultural Change and Democracy: The Human Development Sequence. Cambridge: Cambridge University Press.

James, W. R. 2000. 'Placing the Unborn: On the Social Recognition of New Life.' Anthropology \& Medicine 7 (2): 169-189, https://doi.org/10.1080/713650591.

Jelen, T. G. and C. Wilcox. 2003. 'Causes and Consequences of Public Attitudes toward Abortion: A Review and Research Agenda.' Political Research Quarterly 56 (4): 489-500, https://doi.org/10.1177/106591290305600410.

Kaufman, S. R. and L. M. Morgan. 2005. 'The Anthropology of the Beginnings and Ends of Life.' Annual Review of Anthropology 34: 317-341, https://doi.org/10.1146/annurev.anthro.34.081804.120452.

Kemmelmeier, M., G. Wieczorkowska, H. Erb and E. Burnstein. 2002. 'Individualism, Authoritarianism, and Attitudes Toward Assisted Death: Cross-Cultural, CrossRegional, and Experimental Evidence 1.' Journal of Applied Social Psychology 32 (1): 60-85, https://doi.org/10.1111/j.1559-1816.2002.tb01420.x.

Keown, J. 1992. 'The Law and Practice of Euthanasia in the Netherlands.' Law Quarterly Review 108: 51-78.

Knill, C., C. Adam and S. Hurka. 2015. On the Road to Permissiveness?: Change and Convergence of Moral Regulation in Europe. Oxford: Oxford University Press, https://doi.org/10.1093/acprof:oso/9780198743989.001.0001.

Köneke, V. 2014. 'Trust Increases Euthanasia Acceptance: A Multilevel Analysis Using the European Values Study.' BMC Medical Ethics 15 (1): 15-86, https://doi.org/10.1186/1472-6939-15-86.

Lee, D.-E. D. 2014. 'Explaining Abortion Attitudes: Competing Reproductive Strategies and the Welfare State.' SPICE: Student Perspectives on Institutions, Choices and Ethics 9 (1): 6-47.

Lizza, J. P. 2009. Defining the Beginning and End of Life: Readings on Personal Identity and Bioethics. Baltimore, MA: Johns Hopkins Univrsity Press.

Long, S. O. 2001. 'Negotiating the "Good Death": Japanese Ambivalence about New Ways to Die.' Ethnology 40 (4): 271-289, https://doi.org/10.2307/3773877.

Malpas, P. J., M. K. R. Wilson, N. Rae and M. Johnson. 2014. 'Why Do Older People Oppose Physician-Assisted Dying? A Qualitative Study.' Palliative Medicine 28 (4): 353-359, https://doi.org/10.1177/0269216313511284. 
Milfont, T. L. and R. Fischer. 2010. 'Testing Measurement Invariance across Groups: Applications in Cross-cultural Research.' International Journal of Psychological Research 3 (1): 111-130, https://doi.org/10.21500/20112084.857.

Mishler, W. and R. Rose. 2007. 'Generation, Age, and Time: The Dynamics of Political Learning during Russia's Transformation.' American Journal of Political Science 51 (4): 822-834, https://doi.org/10.1111/j.1540-5907.2007.00283.x.

Ory, S. J., P. Devroey, M. Banker, P. Brinsden, J. Buster, M. Fiadjoe, M. Horton, K. Nygren, P. H. Pai, P. Le Roux and E. Sullivan. 2013. International Federation of Fertility Societies Surveillance 2013. Mount Royal, NJ: IFFS, https://doi.org/10.1016/j.fertnstert.2014.03.045.

Pennings, G. 2004. 'Legal Harmonization and Reproductive Tourism in Europe.' Human Reproduction 19 (12): 2689-2694, https://doi.org/10.1093/humrep/deh486.

Randolph-Seng, B., M. E. Nielsen, B. L. Bottoms and H. Filipas. 2008. 'The Relationship between Ethnicity, Christian Orthodoxy, and Mental Health.' Mental Health, Religion $\mathcal{E}$ Culture 11 (8): 795-805, https://doi.org/10.1080/13674670802084788.

Rudnev, M. and A. Savelkaeva. 2018. 'Public Support for the Right to Euthanasia: Impact of Traditional Religiosity and Autonomy Values across 37 Nations.' International Journal of Comparative Sociology 59 (4): 301-318, https://doi.org/10.1177/0020715218787582.

Salloch, S., S. Wäscher, J. Vollmann and J. Schildmann. 2015. 'The Importance of Trust and the Importance of Trustworthiness.' The American Journal of Bioethics 15 (9): 27-28, https://doi.org/10.1080/15265161.2015.1062166.

Saris, W. E., A. Satorra and W. van der Veld. 2009. 'Testing Structural Equation Models or Detection of Misspecifications?' Structural Equation Modeling: A Multidisciplinary Journal 16 (4): 561-582, https://doi.org/10.1080/10705510903203433.

Sigillo, A. E., M. K. Miller and D. A. Weiser. 2012. 'Attitudes toward Nontraditional Women Using IVF: The Importance of Political Affiliation and Religious Characteristics.' Psychology of Religion and Spirituality 4 (4): 249-263, https://doi.org/10.1037/a0027940.

Soini, S., D. Ibarreta, V. Anastasiadou, S. Aymé, S. Braga, M. Cornel, D. A. Coviello, G. Evers-Kiebooms, J. Geraedts, L. Gianaroli, J. Harper, G. Kosztolanyi, K. Lundin, E. Rodrigues-Cerezo, K. Sermon, J. Sequeiros, L. Tranebjaerg and H. Kääriäinen. 2006. 'The Interface between Assisted Reproductive Technologies and Genetics: Technical, Social, Ethical and Legal Issues.' European Journal of Human Genetics 14 (5): 588-645, https://doi.org/10.1038/sj.ejhg.5201598.

Steck, N., M. Egger, M. Maessen, T. Reisch and M. Zwahlen. 2013. 'Euthanasia and Assisted Suicide in Selected European Countries and US States: Systematic Literature Review.' Medical Care 51 (10): 938-944, https:// doi.org/10.1097/MLR.0b013e3182a0f427.

Sullivan, L. 1993. 'In the Path of Daedalus: Middle-Class Australians' Attitudes to Embryo Research.' British Journal of Sociology 44 (2): 271-302, https:// doi.org/10.2307/591220.

Tormos, R. 2019. The Rhythm of Modernization: How Values Change Over Time. Leiden: Brill, https://doi.org/10.1163/9789004411913.

Turner, L. 1997. ‘Euthanasia and Distinctive Horizons of Moral Reason. Mortality 2 (3): 191-205, https://doi.org/10.1080/713685869.

Uslaner, E. 1999. 'Morality Plays.' Pp. 25-44 in Social Capital and European Democracy, edited by J. W. van Deth, M. Maraffi, K. Newton and P. F. Whiteley. London: Routledge.

van Herk, H. and Y. H. Poortinga. 2012. 'Current and Historical Antecedents of Individual Value Differences across 195 Regions in Europe.' Journal of Cross-Cultural Psychology 43 (8): 1229-1248, https://doi.org/10.1177/0022022111429719. 
Vandenberg, R. J. and C. E. Lance. 2000. 'A Review and Synthesis of the Measurement Invariance Literature: Suggestions, Practices, and Recommendations for Organizational Research.' Organizational Research Methods 3 (1): 4-70, https://doi.org/10.1177/109442810031002.

Verbakel, E. and E. Jaspers. 2010. 'A Comparative Study on Permissiveness toward Euthanasia: Religiosity, Slippery Slope, Autonomy, and Death with Dignity.' Public Opinion Quarterly 74 (1): 109-139, https://doi.org/10.1093/poq/nfp074.

Whisman, M. A. and C. M. Judd. 2016. 'A Cross-national Analysis of Measurement Invariance of the Satisfaction With Life Scale.' Psychological Assessment 28 (2): 239-244, https://doi.org/10.1037/pas0000181.

Zercher, F., P. Schmidt, J. Cieciuch and E. Davidov. 2015. 'The Comparability of the Universalism Value over Time and across Countries in the European Social Survey: Exact vs Approximate Measurement Invariance.' Frontiers in Psychology 6: 733, https://doi.org/10.3389/fpsyg.2015.00733. 